\title{
OR/MS research perspectives in disaster operations management: a literature review
}

\author{
Perspectivas de investigación en OR /MS en la gestión de operaciones de desastres: una
} revisión de la literatura

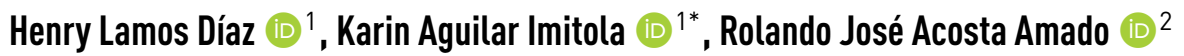 \\ ${ }^{1}$ Escuela de Estudios Industriales y Empresariales, Facultad de Ingenierías Físico-mecánicas, Universidad Industrial de Santander. Cra. \\ 27 Calle 9. A. A. 678. Bucaramanga, Colombia. \\ ${ }^{2}$ Departamento de Ingeniería Industrial, Facultad de Ingeniería, Universidad ICESI. Calle 18 \# 122-135 Pance. A. A. 25608. Cali, Colombia.
}

\section{ARTICLE INFO:}

Received: May 10, 2018

Accepted: March 18, 2019

\section{AVAILABLE ONLINE:}

March 18, 2019

\section{KEYWORDS:}

Disaster, emergency management, humanitarian logistics, operations research

Desastres, gestión de emergencias, logística humanitaria, investigación de operaciones

\begin{abstract}
The unpredictability of natural disasters makes handling their impacts on the population, the environment and the economic resources a challenging decision-making process that must be wisely performed in a very short period of time. An adequate management of operations to disaster response is challenging for decision makers and it has become a topic of significant relevance on a worldwide basis. As a result, academics and practitioners in the field of OR/MS have increased their interest in developing tools to support the decision-making processes on a disaster scenario. This paper surveys the OR/MS literature to identify new trends of increasing interest in disaster operations management (DOM) that have emerged in the last years. A discussion on the gaps that have been successfully addressed in the last years and those that remain opened is also presented. Among the main findings, the recent use of methodologies based on data analysis, such as machine learning and data mining, to address DOM problems was identified. Moreover, a significant increase in the study of operations in the recovery phase and the inclusion of humanitarian objectives in mathematical models was established.
\end{abstract}

RESUMEN: Lo inesperado de los desastres naturales hace que el manejo de sus impactos en la población, el medio ambiente y los recursos económicos sea un proceso de toma de decisiones desafiante que se debe realizar sabiamente en un período de tiempo muy corto. Una gestión adecuada de las operaciones para responder a los desastres es un desafío para quienes toman las decisiones y se ha convertido en un tema de gran relevancia a nivel mundial. Como resultado, los académicos y profesionales en el campo de la OR/MS han aumentado su interés en desarrollar herramientas para apoyar los procesos de toma de decisiones en un escenario de desastre. Este documento estudia la literatura en OR /MS para identificar nuevas tendencias de interés creciente en la gestión de operaciones de desastres (DOM) que han surgido en los últimos cinco años. Una discusión sobre las brechas que se han abordado con éxito en los últimos cinco años y aquellas que permanecen abiertas también se presentan. Entre los principales hallazgos, se identificó el uso reciente de metodologías basadas en el análisis de datos como el Machine Learning y el Data Mining para abordar problemas DOM. Además, un aumento significativo en el estudio de problemas en la fase de recuperación y la inclusión de objetivos humanitarios en los modelos matemáticos.

\section{Introduction}

In recent years, natural disasters have affected an important portion of the population causing a tremendous amount of economic and human losses. In 2017 alone, 318 natural disasters affected 122 countries, causing 9503 human deaths, 96 million victims, and estimated damages

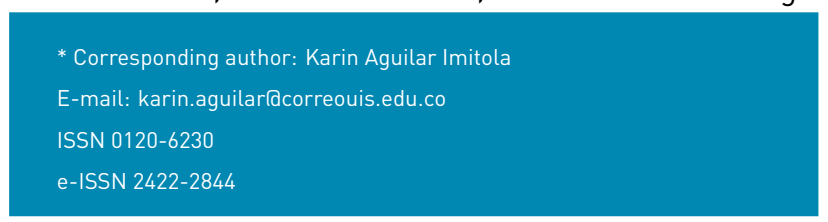

of US $\$ 314$ billion [1]. Although progress has been made in understanding disasters, some societies have a limited capacity to tackle their massive destructive effects. Therefore, it is necessary not only to act on the risk elements of a disaster but also to address the management of response and recovery operations after a disaster.

Disaster management corresponds to the activities carried out before, during and after a disaster, which aim to avoid human losses and economic impacts, as 
well as go back to normal [2]. In this sense, disaster operations management (DOM) provides tools to prepare for disasters, to respond to them, and to provide support and rebuild the society after them.

Since the mid-eighties, the components of an emergency management program have been classified into four stages: mitigation, preparedness, response, and recovery [3]. The mitigation stage involves all the activities that reduce the degree of long-term risk to human life and property from natural and man-made hazards. The preparedness stage aims to develop operational capabilities for responding to a disaster. The response stage includes the actions that are taken immediately before, during or right after a disaster in order to save lives, reduce property damage, or recover easier. Finally, the recovery stage includes all the short-term activities that restore vital life-support systems to minimum operating standards and long-term activities that return life to normalcy. Based on their objectives, uncertainty and duration, the first two stages can be considered as pre-disaster operations, while the last two can be classified as post disaster humanitarian logistics $[4,5]$. A discussion on the stages of disaster management can be found in the work of [6].

Because of the unpredictability of the impacts of disasters, an effective scheme for operations management has been of prime importance in the stages of disaster management. In contrast to a conventional situation of operations management in a company, most decisions in a disaster scenario must be made in advance or shortly after an event occurs, which cause difficulties in decision-making. Therefore, advanced decision-making techniques have played a key role in humanitarian logistic systems. Among the diverse techniques available, Operations Research and Management Science -OR/MS- provide a set of analytical tools that enable the decision-making processes in the DOM context and facilitate the performance improvement of the disaster response systems.

Since different contributions to the field of DOM have been made from the OR/MS discipline, it is useful and necessary to continue exploring the research in this topic. This paper presents the results of a systematic literature review of OR/MS applications in the field of DOM with the aim of identifying new research avenues and challenges, in line with the pioneering works of [2] and [7]. The analysis includes 117 journal articles published between 2010 and 2015, providing temporal continuity to the previously conducted reviews on this topic. Within this period, some disasters of considerable impact occurred in different parts of the world, and received attention from the DOM community, such as the earthquake and tsunami in Japan in 2011, the flooding in China and Pakistan in 2010, and the earthquakes in Haiti and Chile in the same year.

To develop this review, we consider the classification scheme used by [2] and later by [7], excluding the dimension of the classification designed by [8]. The results of every dimension of the classification scheme are obtained by using the bibliometric software Vantage Point. The analysis of the literature shows that some research opportunities identified by [7] have been addressed in the last six years; however, there are still some gaps identified by [2] unexplored. We also identify emerging OR/MS techniques and applications to the field of DOM, and discuss future research directions and challenges that remain unaddressed.

The rest of this paper is organized as follows: In item 1.1 a review of the background and previous studies on the subject is presented. Section 2 presents the methodology for the systematic review, including the search and selection process, as well as the scope of the analysis. Section 3 presents the main results of the analysis based on the classification presented by Galindo and Batta [7]. Section 4 presents a classification of the surveyed papers according to the main problems studied by OR/MS field in DOM. Section 5 proposes future research avenues in this field. Finally, section 6 presents the conclusions and observations of this study.

\subsection{Background}

In recent years, academic and practitioners in the field of OR/MS have increased their attention in developing decision making tools with the aim of responding to different types of disasters with effective decisions. This interest is related not only to the impact that disaster management has in any society, but also to the adaptability of the OR/MS models to the different operations in disaster management. Because of this increasingly interest, a considerable amount of research has been undertaken on this field during the last thirty-six years or so. Remarkably, the last six years have been a dramatic increase on the interest from the OR/MS community to address the DOM research avenues.

[2] were the first authors that conducted a literature review on the OR/MS in the DOM context, in order to give a starting point for interested researchers in disaster operations by identifying research avenues and discussing relevant topics. Their work encompassed the review of 109 documents published between 1980 and 2004, which were classified according to the OR/MS methodology, the stages of disaster management, the type of disaster, the type of research contribution, among others. This study identified seven areas that should be given priority in subsequent research efforts due to their potential impact on DOM 


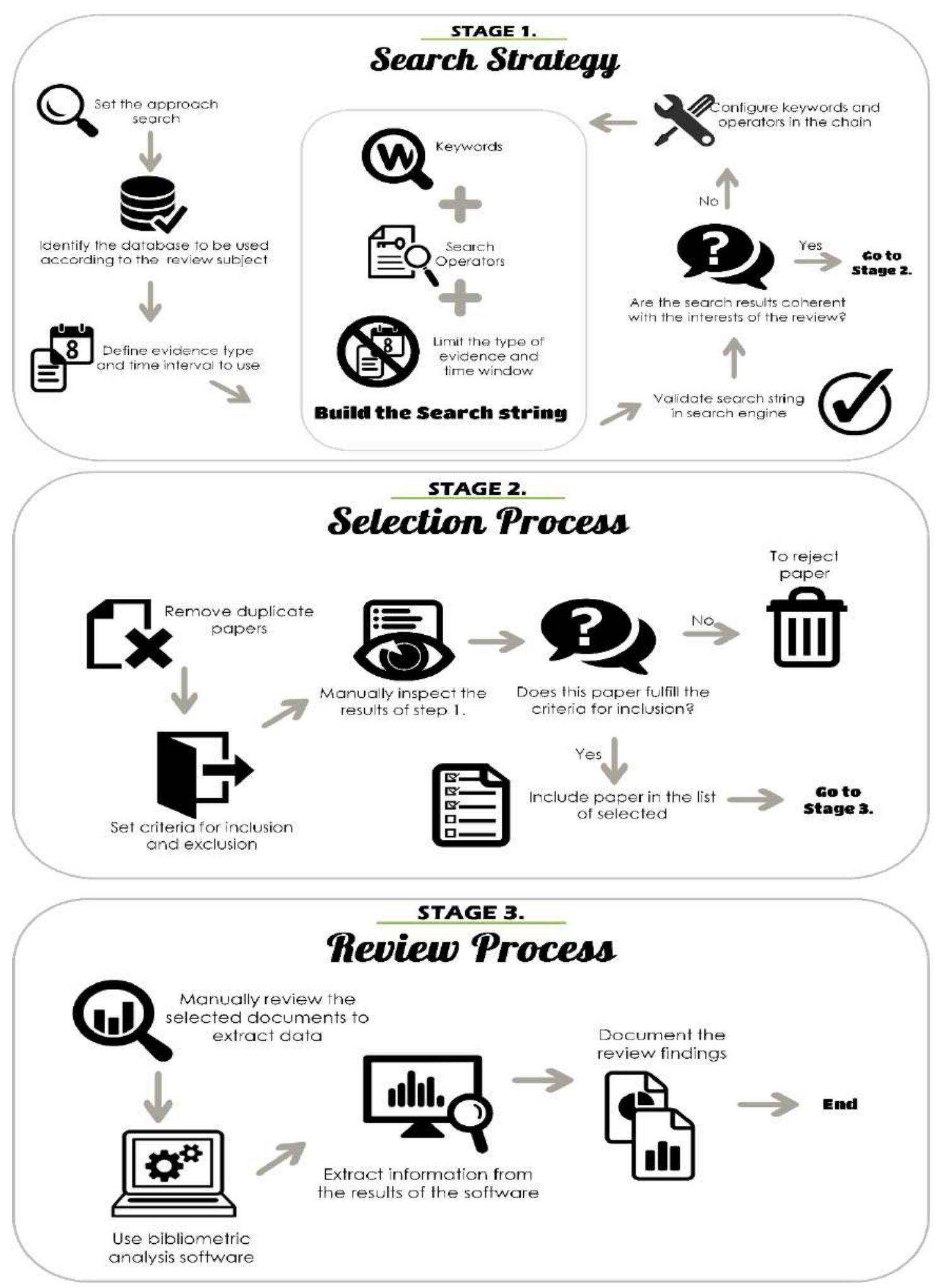

Figure 1 Methodology steps

research: multi-agency research, methods, technology, In this line of work, [7] evaluated how operations research DOM stages, business continuity, infrastructure design, has evolved in terms of DOM and to what extent the gaps and management engineering. identified by [2] had been fully addressed. They reviewed 155 documents published between 2005 and 2010, by 
using the same classification scheme as in [2]. Their findings pointed out that significant developments had not been made in the field of OR/MS in DOM and that some theoretical gaps previously identified by [2] remained unaddressed. They also evaluated the most frequently assumptions in disaster management and identified new research avenues for DOM.

The reviews of [2] and [7] provided an analysis of the research work on OR/MS applications to the DOM field between 1980 and 2010 . They also helped to identify fertile research avenues for this field. Nonetheless, OR/MS community have had an increasingly interest in the DOM field in the last six years, remaining unclear how the research perspectives on this field have evolved. Are there novel research gaps that have been identified during the last six years? Have there been emerging OR/MS applications involving new techniques to answer new questions in DOM?

Other literature reviews on DOM were published after the work of [2]. [9] proposed a framework to distinguish between the actors, the phases and the logistic processes by making a parallel between humanitarian and commercial logistics. [10] conducted a systematic review in disaster management including documents published between 1980 and 2006, with the aim of contributing to the existing knowledge about disaster management, and defining the state of the art of the discipline at that time. [11] focused on the Operation Research -ORliterature applied to emergency response between the years 1965 and 2007. They also offered an explanation of some existing paradoxical challenges in the DOM field from the OR perspective. [12] analyzed the challenges in humanitarian relief chains, described the current and emerging practices of disaster relief, and evaluated the adaptability of the humanitarian relief environments.

In [13] categorized the research papers in humanitarian logistics considering the theory of constraints and the literature of information systems management. Later, [14] focused on the literature of vehicle routing problems to deliver goods and services in the regions affected by a disaster. They classified the research work into four categories: assignment policies, evaluation of needs, demand and supply uncertainty, and vehicles and routes characteristics. [15] classified the literature of emergency logistics in three types of problems: service location, aid distribution, and victims transportation. [16] proposed a framework that should help decision-makers in the field of humanitarian logistics to find, compare, and apply OR models considering the type of decisions, the decision criteria and metrics, as well as the methodology and assumptions. [17] centered their discussion in OR models with some stochastic component applied to DOM, along with an analysis of the techniques used to model and solve them. [18] analyzed the research progress made on evolutionary algorithms applied to relief operations.

\section{Scope and methodology}

The methodology to carry out this study is adapted from the guidelines proposed by [19] and [20]. It has three components: a search strategy, a selection process, and a review process (Figure 1). This methodology can be summarized as follows:

a) Objectives and general needs of the review. The scope of this study is the OR/MS in DOM, therefore, it was limited to the definitions of OR/MS, disasters and DOM. Considering these definitions, all the types of disasters were considered according to the International Federation of Red Cross and Red Crescent Societies (IFRC). For more information, the interested reader can refer to www. ifrc.org.

b) Electronic search. A preliminary search allowed us to identify that the journals with the highest impact in the research area of this study are found in the ISI's Web of Science Core collection, so this database was taken as the main source. A search of keywords was conducted in the main collection of the ISI Web of Science based on the search process of [2] and [7]. We used the following keywords: "disaster management", "emergency logistics", "humanitarian logistics", "relief operations", "disaster relief", "disaster response", "humanitarian supply chain", "catastrophe" and their extensions. These descriptors were searched on the title, abstract and keywords. The research work related with the fields of medicine, health, politics, geophysics, biology, psychology, social sciences, infrastructure, and electronics were filtered through pertinent boolean operators.

c) Application of inclusion and exclusion criteria. Inclusion and exclusion criteria were defined to determine the documents aligned to this study. A document was included if it was an English written journal article published between 2010 and 2015, whose content was related with the use of any OR/MS technique in the study, comprehension, or solution of some operation in the DOM. The results were filtered by making use of the OR/MS category at the database. We did not include books, book chapters, and conference proceedings in the search process. In addition, publications that address emergencies in commercial supply chains were excluded. With the aim of reducing the number of papers, a manual exploration of the documents was performed by inspecting the titles and abstracts. We used the software Vantage Point to eliminated duplicates. 
Table 1 Summary our statistics and comparison to those from [7], and [2]

\begin{tabular}{|c|c|c|c|}
\hline & Our research & Galindo and Batta [7] & Altay and Green [2] \\
\hline \multirow[t]{2}{*}{ Number of articles } & 117 & 155 & 109 \\
\hline & $\%$ & $\%$ & $\%$ \\
\hline \multicolumn{4}{|l|}{ Authors nationality } \\
\hline USA & 35.9 & 52.9 & 43.1 \\
\hline Other nations & 44.4 & 28.4 & 42.2 \\
\hline International & 19.7 & 18.7 & 14.7 \\
\hline \multicolumn{4}{|l|}{ Methodology } \\
\hline Math Programming & 40.2 & 23.1 & 32.1 \\
\hline Stochastic Programming & 12.0 & 9.6 & 3.7 \\
\hline Decision Theory & 11.1 & 9.0 & 10.1 \\
\hline Conceptual Analysis & 7.7 & 16.0 & NA \\
\hline Simulation & 5.1 & 9.0 & 11.9 \\
\hline Fuzzy sets & 3.4 & 1.9 & 5.5 \\
\hline Systems Dynamics & 3.4 & 1.3 & 1.8 \\
\hline Constraint Programming & 0.0 & 0.6 & 0.9 \\
\hline Experts Systems and Al & 0.0 & 3.8 & 3.7 \\
\hline Probability and Statistics & 1.7 & 6.4 & 19.2 \\
\hline Data Mining and ML & 1.7 & NA & NA \\
\hline Game Theory & 0.9 & 1.3 & NA \\
\hline Queuing Theory & 0.0 & 0.6 & 9.2 \\
\hline Soft OR & 0.0 & 1.3 & 0.9 \\
\hline Combined Approach & 12.8 & 11.6 & NA \\
\hline \multicolumn{4}{|l|}{ Operational Stage } \\
\hline Mitigation & 1.71 & 23.9 & 44.0 \\
\hline Preparedness & 20.51 & 28.4 & 21.1 \\
\hline Response & 48.72 & 33.5 & 23.9 \\
\hline Recovery & 1.71 & 3.2 & 11.0 \\
\hline Multiple Stages & 17.95 & 11 & 0.0 \\
\hline \multirow{2}{*}{\multicolumn{4}{|c|}{$\overline{\text { Disaster type }}$}} \\
\hline & & & \\
\hline Natural & 36.8 & 20.0 & 28.4 \\
\hline Men-Made & 9.4 & 5.8 & 33.1 \\
\hline Humanitarian & 6.8 & 2.6 & 0.9 \\
\hline All disasters & 47.0 & 71.6 & 37.6 \\
\hline \multicolumn{4}{|l|}{$\bar{R}$ Reséarch contribution } \\
\hline Theory & 24.8 & 19.3 & 26.6 \\
\hline Model & 29.9 & 75.5 & 57.8 \\
\hline Application & 45.3 & 5.2 & 15.6 \\
\hline
\end{tabular}

d) Data Analysis. After conducting the previous steps, a total of 117 articles were chosen for the review process. The results of the bibliographic analysis were generated by using the software Vantage Point 9.0, Search Technology, Inc.

There is certain subjectivity in the selection of the literature to carry out the analysis. However, this paper is not an exhaustive bibliographical study but it is the result of a systematic and scientific review methodology in the specific field of OR/MS in DOM.

\section{Research perspectives of OR/MS in DOM}

A total of 117 journal articles were included in this review, including 84 references that were published in OR/MS mainstream scientific journals ranked in Q1 and Q2 according to SClmago Journal Rank ISJR, 2015). Some of these journals include Journal of Operations Management, Omega, Operations Research, Transportation Research-Part B, International Journal of Production Economics, Production and Operations Management, and Computers and Operations Research. 
A comparison of the number of papers included in this study and published in OR/MS journals with these reported by [7], revealed that most papers in the DOM area (Figure 2) for both time frames were published in Computers \& Operations Research, Transportation Research-Part E, and the European Journal of Operational Research (EJOR). Nonetheless, a remarkable increase in the number of DOM publications was also found in journals such as OR Spektrum and Computers and Operations Research, with respect to the findings of [7]. This might have occurred because of special issues in Optimization of Disaster Relief and Emergency Management in 2011 and 2014, respectively. In the last six years, the topics related with transportation and logistics in DOM have received greater attention, with a significant number of contributions in specialized journals including evacuation research, aid distribution, and location of support facilities. Some scientific journals that published papers on this topic during the observed time frame, which were not reported by [7], were Transportation Research Part $E$ and Part $B$.

The remaining 33 articles were published in journals of engineering, safety and reliability, and mathematical applications. Some remarking journals included Safety Science, IIE Transactions, and Expert Systems with Applications. Table 1 presents a synthesis of the

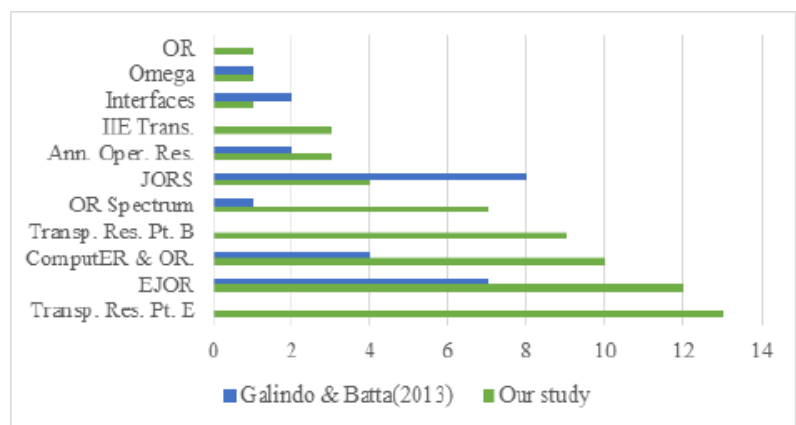

Figure 2 Number of DOM articles in the main OR/MS journals

papers classification by categories, which was carried out according to the OR/MS methodology, the type of disaster, the phase in the disaster cycle, and the type of contribution.

\subsection{Authors affiliation}

The category of authors nationality (Table 1) indicates the affiliation of them. Likewise, the points represented in Figure 3 correspond to the total number of articles per country, where the points that connect different countries correspond to papers in co-authorship. In this sense, we observed that most research papers were produced in the USA and a significant amount of them were published in co-authorship with Turkish researchers. West Europe and Asia were regions with significant contributions, where
France and China were the corresponding leaders. In line with the results of [7], we found that contributions from Latin America and Oceania researchers continued to be low during the time frame of this study.

Chile is the only country in Latin America with a contribution to this field during the time frame, however, this study was included in the International category since it was coauthored by researchers from different nationalities [2]. The category International certainly had an increase in the number of publications with respect to the results reported by [7]. Nonetheless, our results suggest that the tendency of working with colleagues of the same nationality has increased which is evident in the category other nations (Figure 3).

\subsection{Methodology}

The analysis of the selected references showed that mathematical programming continues to be the most popular OR/MS methodology in DOM and it has been mainly used in the response phase [21-24]. Stochastic programming has been one of the most used methodologies as a result of the inherent uncertainty of natural disasters. It has been mainly used to solve problems that consider multiple stages in the cycle of a disaster [25, 26]. For instance, [27] tried to improve the transport network and reduce the expected post-disaster response time through pre-disaster investment decisions using a bi-level stochastic optimization model.

As the Figure 4 shows, the number of research papers on mathematical programming, stochastic programming, and combined methodologies has been a sustained increase. However, a particular trend could not be observed for studies involving simulation and decision theory, which are two useful techniques to support decision-making processes under uncertainty.

We also consider the scientific articles that carried out a conceptual analysis, including literature reviews and other documents where no particular analytical methodology was applied [28, 29].

Data mining and machine learning techniques have received little attention in the DOM field. They were not mentioned in the works of [2] and [7], which covered a period of 30 years. Nonetheless, we found that new OR/MS techniques are contributing to the field of DOM. For example, multiple linear regression, discriminant analysis, classification trees, and other machine learning techniques have been used to support decision making systems in the assessment of a disaster [30]. 


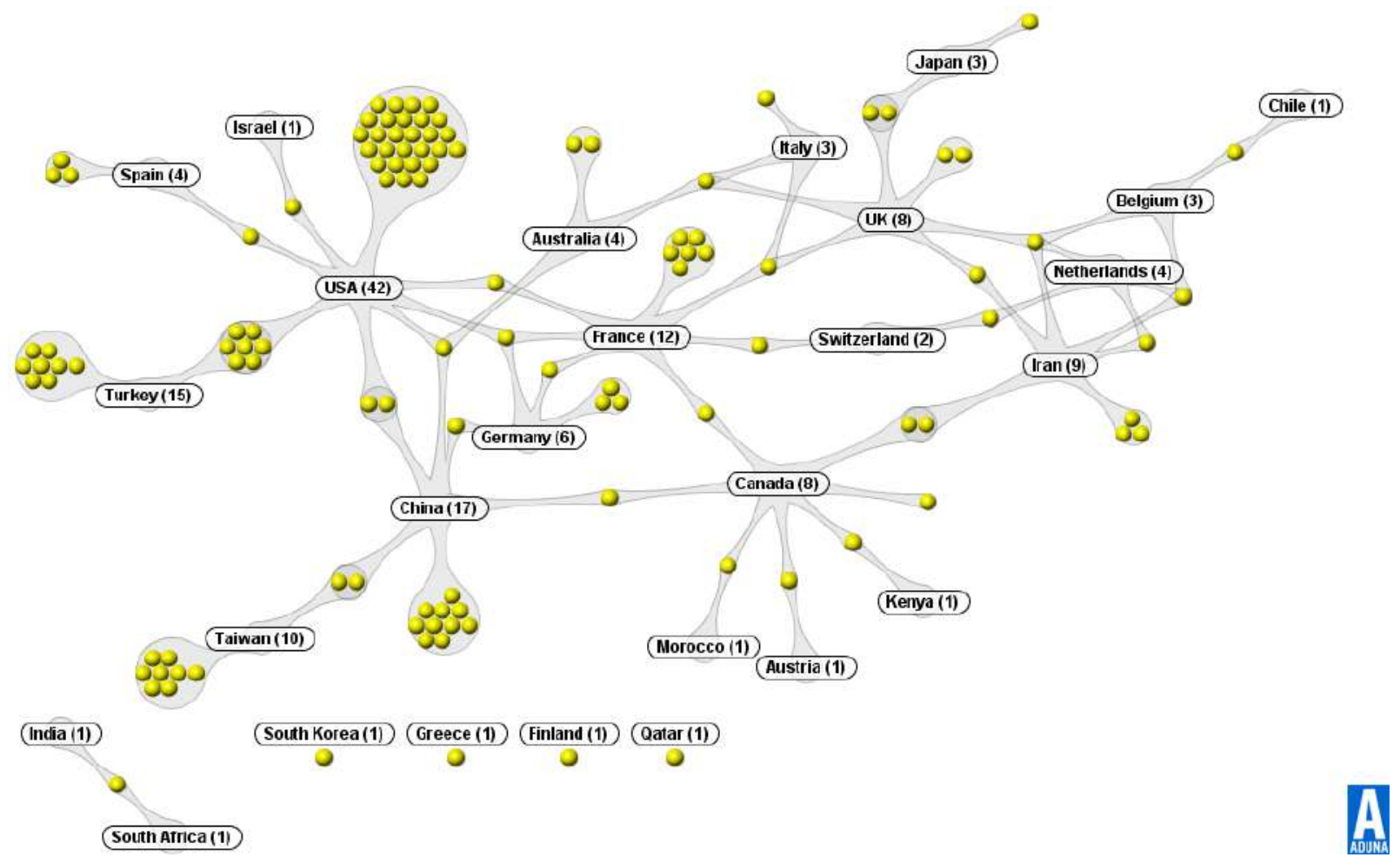

Figure 3 Aduna cluster map of authorship relation by country

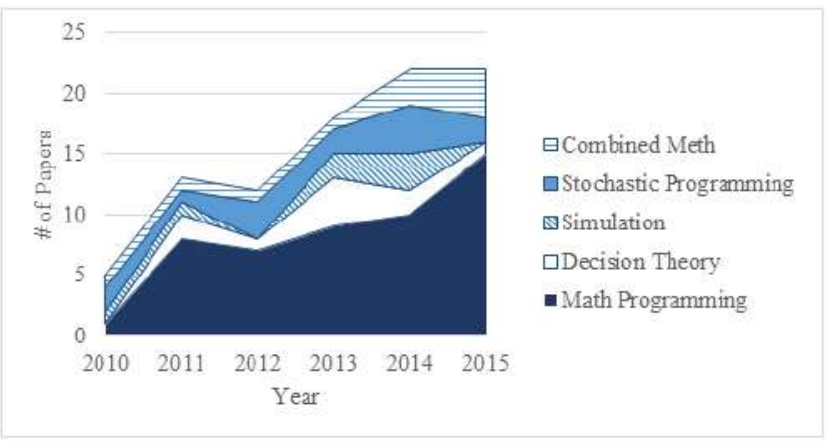

Figure 4 Timeline of the main OR/MS methodologies

\subsection{Stages in disaster management}

Most papers sought to solve problems in the response phase, an ongoing trend since the work of [2]. By contrast, the publications that addressed the mitigation phase decreased considerably with respect to the last two reviews. Other papers were focused on multiple stages of disaster management. In these cases, the authors proposed models to solve problems in pre-disaster (mitigation and preparedness) and post-disaster (response and recoveryl operations. For example, [31] studied sheltering network planning and operations for natural disaster preparedness and response. The locations, capacities and resources of the new refuges were decided in the preparedness phase, while the distribution of evacuees and resources to the new refuges are planned to the response phase.

Regarding to the recovery phase, some studies applied OR/MS models to address logistic activities such as the removal of debris [32, 33] and the repair of roads [34]. These activities were identified by [2] as research gaps within the recovery phase, and continue being an unexplored research opportunity for OR/MS on DOM. Other publications were not clearly framed in a phase of disaster management, however, these documents presented generalized problems or methods that can be used in any phase of the disaster cycle [35-37].

\subsection{Type of disaster}

Natural disasters have received more attention in OR/MS, which is evidenced by an increase of research papers in this category regarding to [7]. Particularly, $62 \%$ of the studies of natural disasters were applied cases, which can be related with the occurrence of different disruptive events since 2011, including earthquakes, tsunamis, and extreme weather conditions. A significant progress was evidenced in the humanitarian category with respect to the findings of [7] and [2], where OR/MS techniques were applied in studies of epidemics [38] and famines [39]. Other authors carried out studies in international aid entities $[40,41]$. Finally, some theoretical articles are grouped in the category All disasters, as they did not specify features 
of a disaster, and focused on any kind of threat [28, 42-44] (Figure 5).

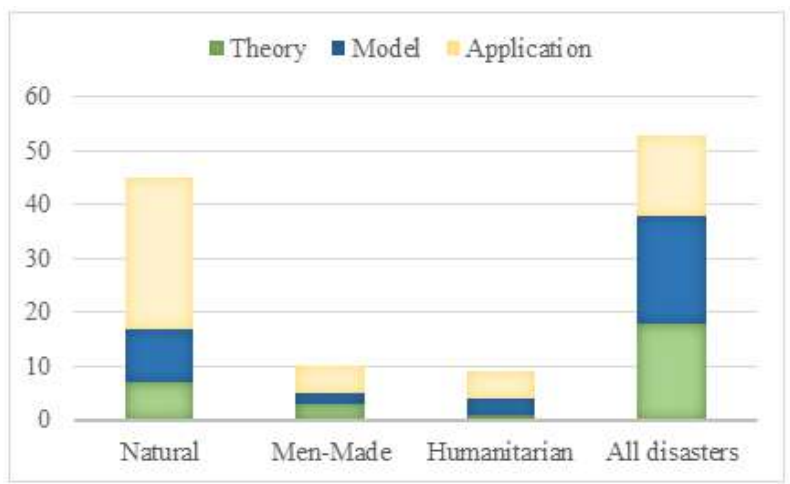

Figure $\mathbf{5}$ Distribution of the research work by disaster types

\subsection{Research contribution}

Based on the classification proposed by [2], and the definitions of each category presented in [7], the articles are classified into three categories based on their contribution to DOM knowledge: Theory, Model, and Application.

Articles that develop reflections on a particular topic, test hypotheses, present a framework, study the behavior of a system, define principles or taxonomies, or review literature, are classified in the Theory category. The Model category includes publications that address analytical models to solve or analyze a problem. Finally, articles that develop a computational tool or prototype lincluding Decision Support Systems -DSS-) are included in the Application category.

In comparison with the results found in [7], the proportion of articles with applications has increased and the proportion of studies focused on models have decreased. We consider that these variations are related to the need to develop agile and efficient tools that support the decision-making process in the field of DOM, specifically, the development of applications for solving the analytical models that have been recently formulated in this area. As shown in Figure 6, most of contributions in the different phases of the disaster cycle have been in the Application category, mainly in the response and preparedness phases. The theoretical articles have been mainly in the response phase, while the articles that refer to multiple stages are concentrated in the Model category.

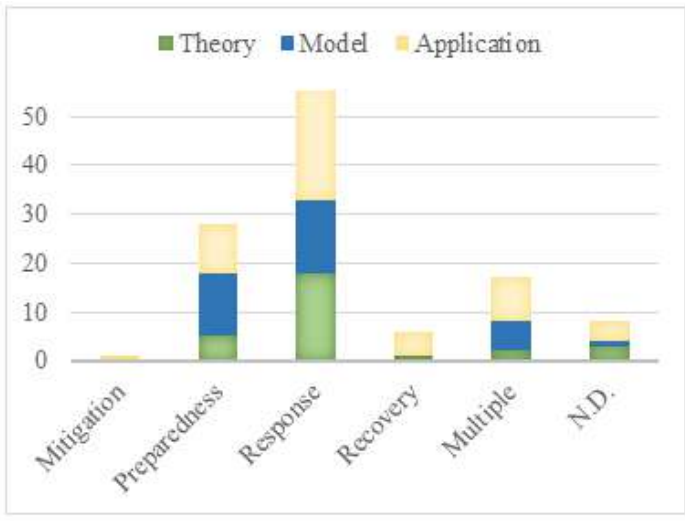

Figure 6 Distribution of research work by disaster management stages

\section{Concentration areas in DOM research}

The research work in DOM has been focused on three phases in the disaster cycle: the preparedness (pre-disaster), the response, and the recovery (post-disaster). Most operations of each phase have been studied from the OR/MS field to improve their understanding and development. In this sense, we divided the literature in five categories based on the main problems identified in the DOM research work: (1) location and network design, (2) transportation, (3) location and transportation, (4) inventory, and (5) other less popular contributions in DOM (Table 2).

One of the main operations in disaster management is the network design, which includes the location of any facility inside the humanitarian logistic network. For this operation, the research work has been focused on the response phase, where mathematical programming is the most used method. Location has been modeled mainly through the Facility Location Problem (FLP) and mono-objective covering models during a single period. Some multi-objective studies seeking the minimization of costs, unsatisfied demand or time were first presented in the work of [2], and were complemented by the works of $[21,33,49]$. Other contributions of network design used stochastic models to address the uncertainty in the estimation of disaster impacts. This uncertainty is not only associated with the demand, but also with the supplies, the cost of acquisition, and transportation, among other characteristics of the disaster $[27,48,49,53,57]$.

The transportation category includes the distribution of supplies, the transportation of victims, the evacuation of the affected population, and the search and rescue operations (S\&RO). Most operations were modeled as a variant of the Vehicle Routing Problem (VRP) or as a 
Table 2 Research problems on DOM in chronological order

\begin{tabular}{|c|c|}
\hline $\begin{array}{l}\text { Research Problem } \\
\text { (Number of studies) }\end{array}$ & Contributions \\
\hline Network design-Location (27) & 12]; [45]; [41, 46, 47]; [21]; [48- \\
\hline rtation (37) & [24], [63-71] \\
\hline ransportatic & {$[3$} \\
\hline Inventory (14) & ]; [40]; \\
\hline Other topics (30) & [23]; [114]; [29]; [115]; [30];[32-34]; [116-118]; [38]; [119-125]; [36];[126-134] \\
\hline
\end{tabular}

case of last mile distribution. To solve the transportation problem, a wide variety of integer programming models has been proposed, including Mixed Integer Programming $[75,84,99]$. Other studies used heuristic and metaheuristic solution schemes, such as genetic algorithms $[76,78]$ and local search [89]. A diverse set of optimization criteria has been considered in this research field, including efficiency, effectiveness, and equity [135].

Our literature review revealed that most studies in the transportation category has been focused on efficiency (costs) and effectiveness (response time, travel distance, coverage, reliability and safetyl criteria. Equity criteria, which are related to justice, have received little attention because it remains unclear how to model them [44]. According to [135], the simplest way to address equity is to consider the worst case value of a measure of disutility over all groups of people as an objective function. For example, the objective of a distribution problem is defined as a function of the worst travel distance to the nearest depot. So, the final result is a little value when there is inequity among the attention levels. Other equity criteria were also identified in the literature review, including the demand satisfaction, the number of survivors or injured people [24, 70, 80, 84], and the social or psychological costs. For instance, a recent study proposed a method for designing a centralized emergency supply network to minimize the travel distance, the operational cost, and psychological cost [59]. [79] proposed a multi-objective linear programming model for post-disaster debris reverse logistics, where the cost function is the psychological stress experienced by local residents while they are waiting for medical treatment and debris removal. This cost function must be minimized along with the environmental and operational risks.

Category 3 includes contributions that address problems of location and transportation as a whole. In this group, the Location Routing Problem [100], and its variants, the Capacitated Location Routing Problem [102], the Open Location Routing Problem [99], and the Warehouse Location Routing Problem [98] have been the most used. The Covering Tour Problem [22] and the Location-Transportation models [97] have also been used in the DOM context. Most studies in this category were multi-criteria including classic measures of effectiveness such as time, cost, and coverage.

On the other hand, planning (pre-location) and inventory strategies are grouped in the category Inventory. Around half of the contributions in this category dealt with goods pre-location, where the total cost minimization is the common objective. Different methodologies have been used to address the inventory operations, including stochastic programming [25, 26, 104, 105, 111], mathematical programming [103, 106, 108, 110], and systems dynamics [107, 109].

Other papers addressed less popular research problems that represent a valuable contribution to the OR/MS applications in DOM. Some authors were focused on operations of the recovery phase, such as the management of debris (removal, disposition and recycling), the assessment of damages [116], and the restoration of roads [34]. Despite the importance of post-disaster debris management, the studies of OR/MS to support the decision-making processes involved were limited. Table 3 provides a synthesis of the papers found in this area.

Finally, some research contributions were focused on information systems [36, 118, 132], decision support systems -DSS- [24, 30], resource programming $[38,128,129]$, and improvement of infrastructure [114].

\section{Future research perspectives}

This section aims to identify trends and challenges in the research avenues for OR/MS applications in DOM considering three issues indicated in [7]: Actors, Technologies, and the DOM problem. There is no consensus among authors about the operations carried out in each phase of the disaster management cycle. In this sense, an exhaustive study of the operations and their characteristics is still required as a basis for classifying them in the different stages of disaster management cycle. 
Table 3 Main features of debris management research

\begin{tabular}{lcccccc}
\hline Debris Operation & Author & Model & Method & Objectives & Tested & Constraints \\
\hline DCl & Celik, M; et al. [32] & MP & Heu & B & Ac & Cap \\
DCo, DD & Onan, K; et al.[33] & MO & MHeu & C, R & CS & Cap \\
DCo, DD, DR & Hu, Z-H, and Sheu, J-B [120] & LPMO & Ext & C & CS & Cap \\
\hline
\end{tabular}

Debris Operations-DCl: Debris Clearance, DCo: Debris Collection, DD: Debris Disposal, DR: Debris Recycling. Model- MP: Markov Process, MO: Multi-Objective, LP: Linear Program. Solution Method- Heu: Heuristic, MHeu: Metaheuristic, Ext: Exact methods. Objectives- B: Benefit, C: Cost, R: Risk. Tested: Ac: Academic, CS: Case Study. Constraints- Cap: Capacity.

\subsection{Actors}

Within the research perspectives suggested by [2], the development of optimal organizational and network structures is proposed to facilitate communication and coordination in disaster resolution. The lack of coordination is one of the main problems in humanitarian operations [12], mainly due to the interaction of different actors in the logistics chain whose objectives may differ. Although [7] identified some publications that address this perspective, including $[12,63,136]$, they also highlighted the lack of joint research with humanitarian organizations. Our literature review identifies some publications that fill the gaps evidenced in the previous reviews. [41] described the main characteristics of a humanitarian supply chain, and identify three determining factors for coordination in the humanitarian context: mobilization and allocation, coherence and efficiency, as well as empowerment and best practices. They also developed a quantitative model based on business modeling methodologies, which is applied to the response operations of the IFRC. [108] addressed the operation of the United Nations High Commissioner for Refugees (UNHCR) by developing an inventory model to analyze the interaction between a stockpile and relief operations in a refugee camp, subject to budget constraints. [40] in collaboration with CARE International formulated a pre-positioning model of resources to assess the impact on the average response time in humanitarian emergencies, which was used for the pre-positioning of supplies in three different facilities. Other related articles include [46] and [92].

Even though contributions about this perspective are evidenced, the gap identified in [2] and [7] still need to be filled. In this sense, there is an opportunity in OR/MS to establish the needs of the different actors of the humanitarian supply chain, considering the restrictions in the management of knowledge, financial and human resources, as well as operations.

\subsection{Technology}

The models developed for humanitarian logistics and their solution methods need to be integrated into information technologies that facilitate their use in practice. However, the use of new adequate technologies is still unexplored in DOM, as it is stated by [7]. An approach to studies on information systems for humanitarian logistics is presented in [5]. Despite attempts to integrate information system in humanitarian logistics models have been made, the use of advanced technologies is not common [131]. On the one hand, the systems already in use, which are centered in information management, have not integrated optimization tools. For example, [137] compared five professional software for humanitarian logistics -SUMA, LSS, HELIOS, LogistiX and Sahana-, which do not consider disaster management operations such as routing or resource scheduling. On the other hand, most information systems do not have a friendly user interface.

The use of information technologies in humanitarian logistics such as Radio Frequency Identification -RFIDand Geographic Information Systems -GIS- are identified in [131]. Information technologies have the potential to link professionals and researchers in humanitarian logistics, as well as connect different phases of the disaster cycle. Therefore, their application remains an interesting topic to explore in order to consolidate more holistic systems that integrate different phases of the disaster cycle as well as different decisions.

\subsection{Solving DOM problems}

\section{Identification and definition of DOM problems}

[2] and [7] identified a lack of research in recovery-related problems after disaster, however, we found some studies addressing this gap. Operation such debris management $[32,33,138]$, road repair, and damage assessment were identified in some contributions. Nevertheless, there are still many operations of this phase that offer opportunities for research, such as the recovery planning, the restoration of vital systems (power, water, and gas), and the economic recovery or housing-related issues after the disaster. In this sense, it is important to identify the operational characteristics of the recovery activities that can be modeled through OR/MS methods in order to develop new research in this phase. In large scale disasters, different international aid organizations offer their services in the response and recovery phases by distributing goods 
and equipment, but the provision of these services can be affected by conflict of interests when arriving to the disaster site [12]. Therefore, there is a need for addressing the integration of international aid operations with local response plans. Furthermore, recovery planning must be multi-agent so that the organizations involved work on common objectives. Finally, the recovery models must include the financial flows.

The transportation-related problems are common in every phase of the disaster cycle and capture the inherent complexity of the disaster environment. The transportation mode used in the models is a relevant topic to be addressed. Both the physical routes among the entities and the flow of aid resources through air, sea and land transportations modes required to be considered in more realistic scenarios [35]. However, the research contributions have been focused on fleets of land transport vehicles and there are few papers dealing with other transportation modes. The problem objectives have been more centered in speed and demand satisfaction than in operational costs. In this sense, the proper selection of the transportation mode must consider the geographic characteristics of the zone and the dispersion of the population. Contributions based on air transportation considered mainly the use of helicopters [89, 110, 139] while those based on multi-modal transportation proposed different types of vehicles and goods $[28,91]$. Future research work should include other modes of transportation such as maritime and aerial, and consider not only the costs but also the speed and reliability of the delivery.

Recently, the use of drones or unmanned aerial vehicles -UAV- is an option to solve last mile distribution problems in isolated places when the use of other vehicles is expensive in relation to the amount of goods to be distributed, the travel distance, or the landing conditions. [140] proposed a model that seeks to minimize the overall cost of the system by establishing the optimal location of distribution centers, their inventory levels and service regions, and routing drones to supply emergency items. The authors calculated the transportation cost by taking into account different factors of routing, including climbing, hovering, descending, turning, acceleration and constant speed cost. Other studies in OR/MS that implement drones as a transportation mode are presented in [140-142]. [143] suggested that drones could be used to create maps of affected areas, to know the current state of the roads, and to identify critical points where rescue teams have a greater chance of finding victims. The use of drones is an opportunity in humanitarian logistics not only for the aid distribution but also for obtaining information about disaster areas. Therefore, more research from $\mathrm{OR} / \mathrm{MS}$ field is still required.
On the other hand, the flow of heterogeneous goods, equipment, and donations to the disaster zone is called material convergence, which ranges from materials of critical importance to the response, to the flow of low turnover supplies. The convergence of materials represents a major problem in humanitarian logistics due to the conglomeration of unhelpful goods in the affected areas as mentioned by [144]. These supplies cause clogged supply chains and resource consumption in their management. This term is not mentioned in previous literature reviews [2, 7], and there is little research on this subject. [145] provided a comprehensive literature review on the problems related to material convergence. [146] conducted interviews to identify the impact of material convergence on the Colorado floods in 2013, and discussed practices and methods to reduce it. The material convergence is one of the six key areas for improving humanitarian logistics and is a variant of commercial logistics. Although this problem has been identified in various disasters, it has not been addressed in the DOM field.

Recently, different authors have incorporated humanitarian objectives in their research. [147] used the social cost as an objective function for humanitarian logistic models, defining it as the sum of logistic and deprivation costs. The latter corresponded to the economic valuation of human suffering associated with the lack of access to a good or service.

In addition, the maximization of survivors and the minimization of evacuation costs are still challenging issues in the response phase. Only the study of [84] aimed to maximize the number of patients who survive after being injured in a disaster. In the context of survival maximization or victim minimization, is it possible to design a performance measure that allows determining whether the implemented strategies have been successful? and how can such performance measure be included in a mathematical model of the problem?

Regarding to the ethical factors included in service allocation to disaster victims, [7] mentioned that only equity had been considered in the DOM models $[2,24,44,68,83]$ stated that there was a lack of research work that deal ethically with the limitations and conflictive advantages of the objective function in the disaster models. Future work could be focused on proposing modeling strategies that compensate the efficiency and the ethical factors such as equity.

Since commercial chains have been widely studied, some findings could be adopted by humanitarian chains, despite they are clearly different [9]. For example, it 
can be useful to study the adaptability of the disruption models of commercial supply chain in humanitarian chains by considering multiple agents in an integrative way. The coordination of donations also offers research opportunities. On the one hand, the formulation of strategies to control the flow of donated supplies must be addressed, so that the delivery of useless or undesirable items does not occur. On the other hand, the reverse logistics of donations must be considered in the design of humanitarian supply chain.

Finally, business continuity is a critical topic considering that $43 \%$ of the companies affected by serious catastrophes never recovered, and around $30 \%$ of them failed during the following two years [148]. [7] did not find any paper as an answer to the lack of research in the continuity of business after a disaster, as remarked by Altay and Green. However, the contribution of [133], which is identified in the present study, proposed a framework for business continuity and disaster recovery planning after being disrupted by addressing decision problems at all strategic, tactical, and operational levels. They formulated a multi-objective mixed integer linear programming model with the aim of maximizing recovery point and minimizing recovery time objectives. To address the current challenges of business continuity, we also propose the following questions: how could economic impacts be included in business continuity models?, how do the disruptions in the supply chain affect the cycles of inventory rotation?, and how can resilience functions be incorporated in the current models? Although any approach to the resilience issue was not identified in the two latest literature reviews, we found that [149] proposed a multi-criteria approach to capture the compensations between the sturdiness of a system and its speed of recovery in situations where multiple disaster or emergency events occur. The authors extended the concepts regarding the resilience triangle and multiple criteria into sub-events, with the purpose of providing a quantitative measure of resilience by means of a mathematical model. Likewise, other authors tried to establish resilience functions to disasters from analytical [150] and quantitative approaches [151].

\section{Validity of assumptions}

As identified in [7], the construction of real assumptions about the uncertainty of DOM problems remains a challenge. The authors presented a summary of the main assumptions in DOM problems, classifying them into three categories: reasonable, limited, and unreal. Likewise, they mentioned the value of incorporating the coverage probability based on the reliability of the infrastructure.

Some authors addressed conditions that are more realistic by including performance measures related to infrastructure. [24] comprised the reliability and safety of operating routes by defining reliability as the probability of crossing an arch completely, and safety as the probability that a vehicle be assaulted when traveling through an arch. The estimation of parameters requires stochastic and analytical models, as well as the incorporation of new techniques such as machine learning. By analyzing the EM-DAT disaster database and applying machine learning techniques, [30] calculated the values of different variables (e.g. number of deaths) based on the magnitude of an earthquake and the human development index of the region. The use of historical data in the construction of variables for logistic models is fundamental.

Many operations have been modeled in the different phases of the disaster cycle; however, most of the models have not represented realistic conditions. For example, many location-allocation problems of the preparedness phase have been based on static data of the population as a parameter of demand. According to [152], the world proportion of urban population is expected to increase from $54 \%$ to $66 \%$ by 2050 . This phenomenon will produce changes in the demand nodes because of overpopulation and migration inside the cities. In this sense, the consideration of population dynamics could be useful in the operations of disaster preparedness including resource allocation, location-assignment, and inventories. [7] also pointed out the unreal data used in the DOM problems, which include static parameters in travel time, costs and demand.

\section{Methodologies}

Since the research of [7], new methodologies of OR/MS have been used to solve DOM problems, including data mining and machine learning techniques. These techniques are centered in analyzing large data sets and their applications in the DOM field have been mainly focused on DSS. Modeling uncertainty in disaster management remains a challenge. The use of either stochastic or fuzzy programming is a promising way to include the uncertainty in the model parameters. Contributions from stochastic programming have included not only the uncertainty in demand but also the disaster characteristics among the stochastic parameters. For its part, fuzzy programming is still little used.

\section{Applying the solution}

The gap between theory and practice manifested in [2] becomes smaller because of the increase of case studies. Many researchers applied their models to real disasters despite data limitations, which maintain unreal assumptions or the use of simulated data. Some case studies found in this review are those presented in $[33,45,48]$. 
Historical data or information systems in vulnerable regions are required to collect information for the models so that assumptions are diminished.

\section{Conclusions}

This paper presents a literature review of OR/MS in DOM that complements the pioneering works of [2] and [7]. Our classification scheme was similar to the proposal of [7], by comparing our findings with those reported in previous reviews. Despite a significant portion of the findings of [2] still remains, new challenges of growing interest have emerged, and some gaps have been addressed. This study provides a classification of the surveyed literature according to the main problems addressed by the OR/MS in DOM, and open new avenues for future research. As expected from the classification, the transportation problems have received most attention from the OR/MS community in the DOM field. This can be due to transportation operations are in all the stages of the disaster management cycle. Furthermore, as stated by [7], the OR/MS research in DOM have been concentrated in a few areas of the response phase le.g. location-allocation, supply chain management, evacuation and distribution). By contrast, operations in the mitigation phase such as risk assessment and emergency control measures have been less studied. The challenges for the academic community are still associated to the proper modeling of the disaster uncertainty.

Among the main avenues for the future research, we suggest to explore the recovery operations, to increase the research efforts in the area of business continuity area, incorporate humanitarian goals in the models, study the reverse logistics in the supply of donations, integrate robust disaster models with the current technologies, and measure the recovery capacity. We also suggest to continue the development of applied contributions in real scenarios of DOM problems, focusing mainly on developing countries where the degree of vulnerability is higher and the resources are scarce.

Disasters are an ongoing threat for the world, and therefore require to be studied so that their effects are mitigated. OR/MS methods have been used to solve DOM problems and facilitate decision-making processes. The OR/MS research in DOM has evolved since the work of Altay and Green [2]. Theoretically, different optimization models have been studied, including a wide variety of logistic problems, objectives and constraints. From a practical perspective, the researchers have made efforts to build more realistic solutions, and to use case studies. There is still a long way to go by academic community, so the findings and suggestions presented in this paper can contribute to develop OR/MS research in DOM and to fill the gaps that remain unaddressed.

\section{References}

[1] C. for Research on the Epidemiology of Disasters CRED, "Natural disasters in 2017 - lower mortality, higher cost," EM-DAT The International Disaster Database, Brussels, Belgium, Tech. Rep., Mar. 2018.

[2] N. Altay and W. G. Green, "OR/MS research in disaster operations management," Eur. J. Oper. Res., vol. 175, no. 1, pp. 475-493, Nov. 2006.

[3] D. McLoughlin, "A Framework for Integrated Emergency Management," Public Adm. Rev., vol. 45, pp. 165-172, Jan. 1985.

[4] J. Holguín, M. Jaller, L. N. Van, N. Pérez, and T. Wachtendorf, "On the unique features of post-disaster humanitarian logistics," J. Oper. Manag., vol. 30, no. 7-8, pp. 494-506, Nov. 2012.

[5] M. T. Ortuño and et al., "Decision aid models and systems for humanitarian logistics. a survey," in Decision Aid Models for Disaster Management and Emergencies, B. Vitoriano, J. Montero, and D. Ruan, Eds. Paris, Francia: Atlantis Press, 2013, pp. 17-39.

[6] E. Nikbakhsh and R. Z. Farahani, "Humanitarian logistics planning in disaster relief operations," in Logistics Operations and Management: Concepts and Models. Massachusetts, USA: Elsevier Inc, 2011, pp. 291-332.

[7] G. Galindo and R. Batta, "Review of recent developments in OR/MS research in disaster operations management," Eur. J. Oper. Res., vol. 230, no. 2, pp. 201-211, Oct. 2013.

[8] M. Denizel, B. Usdiken, and D. Tuncalp, "Drift or Shift? Continuity, Change, and International OR/MS," Operations Research, vol. 51, no. 5, pp. 711-720, 2003.

[9] G. Kovács and K. M. Spens, "Humanitarian logistics in disaster relief operations," Int. J. Phys. Distrib. Logist. Manag., vol. 37, no. 2, pp. 99-114, 2007.

[10] E. Lettieri, C. Masella, and G. Radaelli, "Disaster management: findings from a systematic review," Disaster Prev. Manag., vol. 18, no. 2, pp. 117-136, 2009.

[11] N. C. Simpson and P. G. Hancock, "Fifty years of operational research and emergency response," J. Oper. Res. Soc., vol. 60, no. 1 , pp. S126--S139, May 2009.

[12] B. Balcik, B. M. Beamon, C. C. Krejci, K. M. Muramatsu, and M. Ramirez, "Coordination in humanitarian relief chains: Practices, challenges and opportunities," Int. J. Prod. Econ., vol. 126, no. 1, pp. 22-34, Jul. 2010.

[13] R. E. Overstreet, D. Hall, J. B. Hanna, and R. K. Rainer, "Research in humanitarian logistics," Humanit. Logist. Supply Chain Manag., vol. 1, no. 2, pp. 114-131, 2011.

[14] L. E. D. la Torre, I. S. Dolinskaya, and K. R. Smilowitz, "Disaster relief routing: Integrating research and practice," Socioecon. Plann. Sci., vol. 46, no. 1, pp. 88-97, Mar. 2012.

[15] A. M. Caunhye, X. Nie, and S. Pokharel, "Optimization models in emergency logistics: A literature review," Socioecon. Plann. Sci., vol. 46, no. 1, pp. 4-13, Mar. 2012.

[16] H. Gösling and J. Geldermann, "A framework to compare or models for humanitarian logistics," Procedia Eng., vol. 78, pp. 22-28, 2014.

[17] M. C. Hoyos, R. S. Morales, and R. Akhavan, “OR models with stochastic components in disaster operations management: A literature survey," Aerosp. and Electron. Syst., vol. 29, no. 25, pp. 12-17, Mar. 2014.

[18] Y. Zheng, S. Yong, and H. Ling, "Evolutionary optimization for disaster relief operations: A survey," Appl. Soft Comput. J., vol. 27, pp. 553-566, Feb. 2015.

[19] J. Biolchini, P. Gomes, A. C. Cruz, and G. Horta, "Systematic review in software engineering," Syst. Eng. Comput. Sci. Dep. "COPPE/UFRJ, Rio de Janeiro, Tech. Rep. RT-ES679/05, May 2005.

[20] B. Kitchenham and S. Charters, "Guidelines for performing systematic literature reviews in software engineering," Keele 
University and Durham University, Tech. Rep. EBSE 2007-001, 2007.

[21] N. Görmez, M. Köksalan, and F. S. Salman, "Locating disaster response facilities in istanbul," J. Oper. Res. Soc., vol. 62, no. 7, pp. 1239-1252, Jul. 2011.

[22] Z. Naji, J. Renaud, A. Ruiz, and M. Salari, "A covering tour approach to the location of satellite distribution centers to supply humanitarian aid," Eur. J. Oper. Res., vol. 222, no. 3, pp. 596-605, Nov. 2012.

[23] J. Biing, "Dynamic relief-demand management for emergency logistics operations under large-scale disasters," Transp. Res. Part E Logist. Transp. Rev., vol. 46, no. 1, pp. 1-17, Jan. 2010.

[24] B. Vitoriano, M. T. Ortuno, G. Tirado, and J. Montero, “A multi-criteria optimization model for humanitarian aid distribution," J. Glob. Optim., vol. 51, no. 2, pp. 189-208, Oct. 2011.

[25] R. A. Garrido, P. Lamas, and F. J. Pino, "A stochastic programming approach for floods emergency logistics," Transp. Res. Part E Logist. Transp. Rev., pp. 18-31, Mar. 2015.

[26] C. G. Rawls and M. A. Turnquist, "Pre-positioning of emergency supplies for disaster response," Transp. Res. Part B Methodol., vol. 44, no. 4, pp. 521-534, May 2010.

[27] L. Du and S. Peeta, "A Stochastic Optimization Model to Reduce Expected Post-Disaster Response Time Through Pre-Disaster Investment Decisions," Networks Spat. Econ., vol. 14, no. 2, pp. 271-295, Jun. 2014

[28] L. Özdamar and O. Demir, "A hierarchical clustering and routing procedure for large scale disaster relief logistics planning," Transp. Res. Part E Logist. Transp. Rev., vol. 48, no. 3, pp. 591-602, May 2012.

[29] C. Thévenaz and S. L. Resodihardjo, "All the best laid plans...conditions impeding proper emergency respons," Int. J. Prod. Econ., vol. 126, no. 1, pp. 7-21, Jul. 2010.

[30] J. T. Rodríguez, B. Vitoriano, J. Montero, and V. Kecman, "A disaster-severity assessment DSS comparative analysis," $O R$ Spectr., vol. 33, no. 3, pp. 451-479, Jul. 2011.

[31] J. T. Rodríguez, B. Vitoriano, J. Montero, and V. Kecman, "Sheltering network planning and management with a case in the gulf coast region," Int. J. Prod. Econ., vol. 131, no. 2, pp. 431-440, Jun. 2011.

[32] M. Çelik, . Ergun, and P. Keskinocak, "The post-disaster debris clearance problem under incomplete information," Oper. Res., vol. 63, no. 1, pp. 65-85, Jan. 2015.

[33] K. Onan, F. Ulengin, and B. Sennaroglu, "An evolutionary multi-objective optimization approach to disaster waste management: A case study of istanbul, turkey," Expert Syst. Appl., vol. 42, no. 22, pp. 8850-8857, Dec. 2015.

[34] S. Yan, C. K. Lin, and S. Y. Chen, "Optimal scheduling of logistical support for an emergency roadway repair work schedule," Eng. Optim., vol. 44, no. 9, pp. 1035-1055, Dec. 2012.

[35] J. M. Day, "Fostering emergent resilience: the complex adaptive supply network of disaster relief," Int. J. Prod. Res., vol. 52, no. 7, pp. 1970-1988, 2014.

[36] J. Li, Q. Li, C. Liu, S. U. Khan, and N. Ghani, "Community-based collaborative information system for emergency management," Comput. Oper. Res., vol. 42, pp. 116-124, Feb. 2014.

[37] S. Mohan, M. Gopalakrishnan, and P. J. Mizzi, "Improving the efficiency of a non-profit supply chain for the food insecureg," Int. J. Prod. Econ., vol. 143, no. 2, pp. 248-255, Jun. 2013.

[38] N. P. Rachaniotis, T. K. Dasaklis, and C. P. Pappis, "A deterministic resource scheduling model in epidemic control: A case study," Eur. J. Oper. Res., vol. 216, no. 1, pp. 225-231, Jan. 2012.

[39] M. E. Rancourt, J. F. Cordeau, G. Laporte, and B. Watkins, "Tactical network planning for food aid distribution in kenya," Comput. Oper. Res., vol. 56, pp. 68-83, Apr. 2015.

[40] S. Duran, M. A. Gutierrez, and P. Keskinocak, "Pre-positioning of emergency items for care international," Interfaces, vol. 41, no. 3, pp. 223-237, May 2011.

[41] A. Charles and M. Lauras, "An enterprise modelling approach for better optimisation modelling: application to the humanitarian relief chain coordination problem," OR Spectr., vol. 33, no. 3, pp.
815-841, Jul. 2011.

[42] I. Akgün, F. Gümüșbuğa, and B. Tansel, "Risk based facility location by using fault tree analysis in disaster management," Omega, vol. 52, pp. 168-179, Apr. 2015

[43] M. Besiou, A. J. P. Martinez, and L. N. V. Wassenhove, "Vehicle supply chains in humanitarian operations: Decentralization, operational mix, and earmarked funding," Prod. Oper. Manag., vol. 23, no. 1, pp. 1950-1965, Nov. 2014.

[44] M. Huang, K. Smilowitz, and B. Balcik, "Models for relief routing: Equity, efficiency and efficacy," Transp. Res. Part E Logist. Transp. Rev., vol. 48, no. 1, pp. 2-18, Jan. 2012.

[45] O. Ergun, J. L. Heier, P. Keskinocak, and J. L. Swann, “Waffle house restaurants hurricane response: A case study," Int. J. Prod. Econ., vol. 126, no. 1, pp. 111-120, Jul. 2010.

[46] A. Gatignon, L. N. V. Wassenhove, and A. Charles, "The yogyakarta earthquake: Humanitarian relief through ifrc's decentralized supply chain," Int. J. Prod. Econ., vol. 126, no. 1, pp. 102-110, Jul. 2010.

[47] R. Oloruntoba, "An analysis of the cyclone larry emergency relief chain: Some key success factors," Int. J. Prod. Econ., vol. 126, no. 1, pp. 85-101, Jul. 2010.

[48] A. Martel, A. Benmoussa, M. Chouinard, W. Klibi, and O. Kettani, "Designing global supply networks for conflict or disaster support: the case of the canadian armed forces," J. Oper. Res. Soc., vol. 64, no. 4, pp. 577-596, Apr. 2013.

[49] N. Noyan, "Risk-averse two-stage stochastic programming with an application to disaster management," Comput. Oper. Res., vol. 39, no. 3, pp. 541-559, Mar. 2012.

[50] L. N. V. Wassenhove and A. J. Pedraza, "Using OR to adapt supply chain management best practices to humanitarian logistics," Int. Trans. Oper. Res., vol. 19, no. 1-2, pp. 307-322, Jan. 2012.

[51] J. H. Zhang, J. Li, and Z. P. Liu, "Multiple-resource and multiple-depot emergency response problem considering secondary disasters," Expert Syst. Appl., vol. 39, no. 12, pp. 11 066-11 071, Sep. 2012.

[52] N. Altay, "Capability-based resource allocation for effective disaster response," IMA J. Manag. Math., vol. 24, no. 2, pp. 253-266, Apr. 2013.

[53] A. Bozorgi, M. S. Jabalameli, and S. M. J. Mirzapour, "A multi-objective robust stochastic programming model for disaster relief logistics under uncertainty," OR Spectr., vol. 35, no. 4, pp. 905-933, Nov. 2013.

[54] C. C. Lu, "Robust weighted vertex p-center model considering uncertain data: An application to emergency management," Eur. J. Oper. Res., vol. 230, no. 1, pp. 113-121, Oct. 2013.

[55] C. C. Lu and J. B. Sheu, "Robust vertex p-center model for locating urgent relief distribution centers," Comput. Oper. Res., vol. 40, no. 8 , pp. 2128-2137, Aug. 2013.

[56] M. G. H. Bell, A. Fonzone, and C. Polyzoni, "Depot location in degradable transport networks," Transp. Res. Part B Methodol., vol. 66, pp. 148-161, Aug. 2014.

[57] P. Kelle, H. Schneider, and H. Yi, "Decision alternatives between expected cost minimization and worst case scenario in emergency supply-second revision," Int. J. Prod. Econ., vol. 157, pp. 250-260, Nov. 2014.

[58] C. A. Mackenzie and a. J. R. S. K. Barker, “Modeling a severe supply chain disruption and post-disaster decision making with application to the japanese earthquake and tsunami," IEE Trans., vol. 46, no. 12, pp. 1243-1260, 2014.

[59] J. B. Sheu and C. Pan, "A method for designing centralized emergency supply network to respond to large-scale natural disasters," Transp. Res. Part B Methodol., vol. 67, pp. 284-305, Sep. 2014.

[60] D. Khayal, R. Pradhananga, S. Pokharel, and F. Mutlu, "A model for planning locations of temporary distribution facilities for emergency response," Socioecon. Plann. Sci., vol. 52, pp. 22-30, Dec. 2015.

[61] A. Edrissi, M. Nourinejad, and M. J. Roorda, "Transportation network reliability in emergency response," Transp. Res. Part E Logist. Transp. Rev., vol. 80, pp. 56-73, Aug. 2015. 
[62] X. Hong, M. A. Lejeune, and N. Noyan, "Stochastic network design for disaster preparedness," IEE Trans., vol. 47, no. 4, pp. 329-357, 2015.

[63] B. Adivar and A. Mert, "International disaster relief planning with fuzzy credibility," Fuzzy Optim. Decis. Mak., vol. 9, no. 4, pp. 413-433, Dec. 2010.

[64] A. Ben, B. D. Chung, S. R. Mandala, and T. Yao, “Robust optimization for emergency logistics planning: Risk mitigation in humanitarian relief supply chains," Transp. Res. Part B Methodol., vol. 45, no. 8, pp. 1177-1189, Sep. 2011.

[65] D. R. Bish, "Planning for a bus-based evacuation," OR Spectrum, vol. 33, no. 3, pp. 629-654, Jul. 2011

[66] A. W. Ding, "Implementing real-time grouping for fast egress in emergency," Saf. Sci., vol. 49, no. 10, pp. 1404-1411, Dec. 2011.

[67] Z. H. Hu, "A container multimodal transportation scheduling approach based on immune affinity model for emergency relief," Expert Syst. Appl., vol. 38, no. 3, pp. 2632-2639, Mar. 2011.

[68] M. T. Ortuño, G. Tirado, and B. Vitoriano, "A lexicographical goal programming based decision support system for logistics of humanitarian aid," Top, vol. 19, no. 2, pp. 464-479, Dec. 2011

[69] A. J. Pedraza, O. Stapleton, and L. N. V. Wassenhove, "Field vehicle fleet management in humanitarian operations: A case-based approach," J. Oper. Manag., vol. 29, no. 5, pp. 404-421, Jul. 2011.

[70] L. Chen and E. Miller, "Optimal team deployment in urban search and rescue," Transp. Res. Part B Methodol., vol. 46, no. 8, pp. 1984-999, Sep. 2012.

[71] J. Duanmu, M. Chowdhury, K. Taaffe, and C. Jordan, "Buffering in evacuation management for optimal traffic demand distribution," Transp. Res. Part E Logist. Transp. Rev., vol. 48, no. 3, pp. 684-700, May 2012.

[72] M. Liu and L. Zhao, "An integrated and dynamic optimisation model for the multi-level emergency logistics network in anti-bioterrorism system," Int. J. Syst. Sci., vol. 43, no. 3, pp. 1464-1478, 2012

[73] D. R. Bish and H. D. Sherali, "Aggregate-level demand management in evacuation planning," Eur. J. Oper. Res., vol. 224, no. 1, pp. 79-92, Jan. 2013.

[74] J. A. Capote, D. Alvear, O. Abreu, A. Cuesta, and V. Alonso, "A real-time stochastic evacuation model for road tunnels," Saf. Sci., vol. 52, pp. 73-80, Feb. 2013.

[75] D. R. Bish, H. D. Sherali, and A. G. Hobeika, "Optimal evacuation planning using staging and routing," J. Oper. Res. Soc., vol. 65, no. 1, pp. 124-140, Jan. 2014

[76] F. S. Chang, J. S. Wu, C. N. Lee, and H. C. Shen, "Greedy-search-based multi-objective genetic algorithm for emergency logistics scheduling," Expert Systems with Applications, vol. 41, no. 6, pp. 2947-2956, 2014.

[77] R. Faturechi and E. Miller-Hooks, "Travel time resilience of roadway networks under disaster," Transportation Research Part B: Methodological, vol. 70, pp. 47-4, 2014.

[78] M. Goerigk, K. Deghdak, and P. Heßler, "A comprehensive evacuation planning model and genetic solution algorithm," Transp. Res. Part E Logist. Transp. Rev., vol. 71, pp. 82-97, Nov. 2014.

[79] Z. H. Hu, J. B. Sheu, and L. Xiao, "Post-disaster evacuation and temporary resettlement considering panic and panic spread," Transp. Res. Part B Methodol., vol. 69, pp. 112-132, Nov. 2014.

[80] M. Najafi, K. Eshghi, and S. de Leeuw, "A dynamic dispatching and routing model to plan/ re-plan logistics activities in response to an earthquake," OR Spectr., vol. 36, no. 2, pp. 323-356, Mar. 2014.

[81] M. Pen, H. Chen, and M. Zhou, "Modelling and simulating the dynamic environmental factors in post-seismic relief operation," J. Simul., vol. 8, no. 2, pp. 164-178, 2014.

[82] N. Wagner and V. Agrawal, "An agent-based simulation system for concert venue crowd evacuation modeling in the presence of a fire disaster," Expert Syst. Appl., vol. 41, no. 6, pp. 2807-2815, May 2014.

[83] K. Huang, Y. Jiang, Y. Yuan, and L. Zhao, "Modeling multiple humanitarian objectives in emergency response to large-scale disasters," Transp. Res. Part E Logist. Transp. Rev., vol. 75, pp. 1-17, Mar. 2015.

[84] S. Jin, S. Jeong, J. Kim, and K. Kim, "A logistics model for the transport of disaster victims with various injuries and survival probabilities," Ann. Oper. Res., vol. 230, no. 1, pp. 17-33, Jul. 2015.

[85] M. Goerigk, B. Grün, and P. Heßler, "Branch and bound algorithms for the bus evacuation problem," Comput. Oper. Res., vol. 40, no. 12, pp. 301-3020, Dec. 2013.

[86] M. P. Kwan and D. M. Ransberger, "Lidar assisted emergency response: Detection of transport network obstructions caused by major disasters," Comput. Environ. Urban Syst., vol. 34, no. 3, pp. 179-188, May 2010.

[87] H. S. Na and A. Banerjee, "A disaster evacuation network model for transporting multiple priority evacuees," IIE Trans., vol. 47, no. 11, pp. 1287-1299, 2015

[88] J. A. Paul and X. Wang, "Robust optimization for united states department of agriculture food aid bid allocations," Transp. Res. Part E Logist. Transp. Rev., vol. 82, pp. 129-146, Oct. 2015.

[89] J. C. Rivera, H. M. Afsar, and C. Prins, "A multistart iterated local search for the multitrip cumulative capacitated vehicle routing problem," Comput. Optim. Appl., vol. 61, no. 1, pp. 159-187, May 2015.

[90] M. Huang, K. R. Smilowitz, and B. Balcik, "A continuous approximation approach for assessment routing in disaster relief," Transp. Res. Part B Methodol., vol. 50, pp. 20-41, Apr. 2014.

[91] M. Najafi, K. Eshghi, and W. Dullaert, "A multi-objective robust optimization model for logistics planning in the earthquake response phase," Transp. Res. Part E Logist. Transp. Rev., vol. 49, no. 1, pp. 217-249, Jan. 2013.

[92] A. J. P. Martinez and L. N. V. Wassenhove, "Vehicle replacement in the international committee of the red cross," Prod. Oper. Manag., vol. 22, no. 2, pp. 365-376, Mar. 2013.

[93] Y. Song and et al., "Crowd evacuation simulation for bioterrorism in micro-spatial environments based on virtual geographic environments," Saf. Sci., vol. 53, pp. 105-113, Mar. 2013.

[94] X. Zhang, Z. Zhang, Y. Zhang, D. Wei, and Y. Deng, "Route selection for emergency logistics management: A bio-inspired algorithm," Saf. Sci., vol. 54, pp. 87-91, Apr. 2013.

[95] A. M. Anaya, J. Renaud, and A. Ruiz, "Relief distribution networks: a systematic review," Ann. Oper. Res., vol. 223, no. 1, pp. 53-79, Dec. 2014.

[96] H. M. Asfar, C. Prins, and A. C. Santos, “Exact and heuristic algorithms for solving the generalized vehicle routing problem with flexible fleet size," Int. Trans. Oper. Res., vol. 21, no. 1, pp. 153-175, Jan. 2014.

[97] R. Abounacer, M. Rekik, and J. Renaud, "An exact solution approach for multi-objective location-transportation problem for disaster response," Comput. Oper. Res., vol. 41, pp. 83-93, Jan. 2014.

[98] S. Rath and W. J. Gutjahr, "A math-heuristic for the warehouse location-routing problem in disaster relief," Comput. Oper. Res., vol. 42, pp. 25-39, Feb. 2014

[99] H. Wang, L. Du, and S. Ma, "Multi-objective open location-routing model with split delivery for optimized relief distribution in post-earthquake," Transp. Res. Part E Logist. Transp. Rev., vol. 69, pp. 160-179, Sep. 2014.

[100] M. Ahmadi, A. Seifi, and B. Tootooni, "A humanitarian logistics model for disaster relief operation considering network failure and standard relief time: A case study on san francisco district," Transp. Res. Part E Logist. Transp. Rev., vol. 75, pp. 145-163, Mar. 2015.

[101] M. Najafi, R. Z. Farahani, M. P. D. Brito, and W. Dullaert, "Location and distribution management of relief centers: A genetic algorithm approach," Int. J. Inf. Technol. Decis. Mak., vol. 14, no. 4, pp. 769-803, 2015.

[102] Y. Zhang, M. Qi, W. H. Lin, and L. Miao, "A metaheuristic approach to the reliable location routing problem under disruptions," Transp. Res. Part E Logist. Transp. Rev., vol. 83, pp. 90-110, Nov. 2015.

[103] A. M. Campbell and P. C. Jones, "Prepositioning supplies in preparation for disasters," Eur. J. Oper. Res., vol. 209, no. 2, pp. 156-165, Mar. 2011.

[104] R. Das and S. Hanaoka, "Relief inventory modelling with stochastic lead-time and demand," Eur. J. Oper. Res., vol. 235, no. 3, pp. 
616-623, Jun. 2014

[105] A. Döyen, N. Aras, and G. Barbarosollu, “A two-echelon stochastic facility locationmodel for humanitarian relief logistics," Optim. Lett., vol. 6, no. 6, pp. 1123-1145, Aug. 2012.

[106] G. Galindo and R. Batta, "Prepositioning of supplies in preparation for a hurricane under potential destruction of prepositioned supplies," Socioecon. Plann. Sci., vol. 47, no. 1, pp. 20-37, Mar. 2013.

[107] N. Kunz, G. Reiner, and S. Gold, “Investing in disaster management capabilities versus pre-positioning inventory: A new approach to disaster preparedness," Int. J. Prod. Econ., vol. 157, pp. 261-272, Nov. 2014

[108] J. H. McCoy and M. L. Brandeau, “Efficient stockpiling and shipping policies for humanitarian relief: Unhcr's inventory challenge," $O R$ Spectr., vol. 33, no. 3, pp. 673-698, Jul. 2011.

[109] M. Pen, Y. Peng, and H. Chen, "Post-seismic supply chain risk management: A system dynamics disruption analysis approach for inventory and logistics planning," Comput. Oper. Res., vol. 42, pp. 14-24, Feb. 2014

[110] B. Rottkemper, K. Fischer, A. Blecken, and C. Danne, “Inventory relocation for overlapping disaster settings in humanitarian operations," OR Spectr., vol. 33, no. 3, pp. 721-749, Jul. 2011.

[111] J. Salmerón and A. Apte, "Stochastic optimization for natural disaster asset prepositioning," Prod. Oper. Manag., vol. 19, no. 5 , pp. 561-574, Sep. 2010.

[112] S. Taskin and E. J. Lodree, “A bayesian decision model with hurricane forecast updates for emergency supplies inventory management," J. Oper. Res. Soc., vol. 62, no. 6, pp. 1098-1108, Jun. 2011.

[113] V. S. S. Yadavalli, D. K. Sundar, and S. Udayabaskaran, "Two substitutable perishable product disaster inventory systems," Ann. Oper. Res., vol. 233, no. 1, pp. 517-534, Oct. 2015.

[114] S. Peeta, F. Sibel, D. Gunnec, and K. Viswanath, “Pre-disaster investment decisions for strengthening a highway network," Comput. Oper. Res., vol. 37, no. 10, pp. 1708-1719, Oct. 2010.

[115] W. K. Kao, H. M. Chen, and J. S. Chou, "Aseismic ability estimation of school building using predictive data mining models," Expert Syst. Appl., vol. 38, pp. $10252-10263$, Aug. 2011.

[116] C. H. Chien, S. N. Yu, Y. J. Huang, and F. C. Chong, “An efficient framework of emergency response to facilitate disaster recovery for fire-damaged medical equipment - case study at a large medical centre after a fire," Saf. Sci., vol. 49, no. 5, pp. 727-734, Jun. 2011.

[117] Y. Ju, A. Wang, and X. Liu, “Evaluating emergency response capacity by fuzzy AHP and 2-tuple fuzzy linguistic approach," Expert Syst. Appl., vol. 39, no. 8, pp. 6972-6981, Jun. 2012.

[118] M. Nagarajan, D. Shaw, and P. Albores, “Disseminating a warning message to evacuate: A simulation study of the behaviour of neighbours," Eur. J. Oper. Res., vol. 220, no. 3, pp. 810-819, Aug. 2012.

[119] Q. Zou and et al., "Fuzzy risk analysis of flood disasters based on diffused-interior-outer-set model," Expert Syst. Appl., vol. 39, no. 6, pp. 6213-6220, May 2012

[120] Z. H. Hu and J. B. Sheu, “Post-disaster debris reverse logistics management under psychological cost minimization," Transp. Res. Part B Methodol., vol. 55, pp. 118-141, Sep. 2013.

[121] G. Preece, D. Shaw, and H. Hayashi, “Using the viable system model (VSM) to structure information processing complexity in disaster response," Eur. J. Oper. Res., vol. 224, no. 1, pp. 209-218, Jan. 2013.

[122] Y. Ye and N. Liu, "Humanitarian logistics planning for natural disaster response with bayesian information updates," J. Ind. Manag. Optim., vol. 10, no. 3, pp. 665-689, Aug. 2014.

[123] N. Altay and R. Pal, "Information diffusion among agents: Implications for humanitarian operations," Prod. Oper. Manag., vol. 23, no. 6, pp. 1015-1027, Jun. 2014.

[124] J. L. Bruyelle and et al., "Improving the resilience of metro vehicle and passengers for an effective emergency response to terrorist attacks," Saf. Sci., vol. 62, pp. 37-45, Feb. 2014.

[125] W. H. Kang and A. Kliese, "A rapid reliability estimation method for directed acyclic lifeline networks with statistically dependent components," Reliab. Eng. Syst. Saf., vol. 124, pp. 81-91, Apr. 2014.
[126] F. Wex, G. Schryen, S. Feuerriegel, and D. Neumann, “Emergency response in natural disaster management: Allocation and scheduling of rescue units," Eur. J. Oper. Res., vol. 235, no. 3, pp. 697-708, Jun. 2014.

[127] D. T. Wilson, G. I. Hawe, G. Coates, and R. S. Crouch, "Evaluation of centralised and autonomous routing strategies in major incident response," Saf. Sci., vol. 70, pp. 80-88, Dec. 2014.

[128] Y. J. Zheng, H. F. Ling, H. H. Shi, H. S. Chen, and S. Y. Chen, "Emergency railway wagon scheduling by hybrid biogeography-based optimization," Comput. Oper. Res., vol. 43, pp. 1-8, Mar. 2014

[129] K. Lassiter, A. Khademi, and K. M. Taaffe, "A robust optimization approach to volunteer management in humanitarian crises," Int. J. Prod. Econ., vol. 163, pp. 97-111, May 2015.

[130] M. Omidvari, N. Mansouri, and J. Nouri, “A pattern of fire risk assessment and emergency management in educational center laboratories," Saf. Sci., vol. 73, pp. 34-42, Mar. 2015.

[131] L. Ozdamar and M. A. Ertem, "Models, solutions and enabling technologies in humanitarian logistics," Eur. J. Oper. Res., vol. 224, no. 1, pp. 55-65, Jul. 2015.

[132] G. Preece, D. Shaw, and H. Hayashi, "Application of the viable system model to analyse communications structures: A case study of disaster response in japan," Eur. J. Oper. Res., vol. 243, no. 1, pp. 312-322, May 2015.

[133] N. Sahebjamnia, S. A. Torabi, and S. A. Mansouri, “Integrated business continuity and disaster recovery planning: Towards organizational resilience," Eur. J. Oper. Res., vol. 242, no. 1, pp. 261-273, Apr. 2015.

[134] H. Seppänen and K. Virrantaus, “Shared situational awareness and information quality in disaster management," Saf. Sci., vol. 77, pp. 112-122, Aug. 2015.

[135] W. J. Gutjahr and P. C. Nolz, "Multicriteria optimization in humanitarian aid," Eur. J. Oper. Res., vol. 252, no. 2, pp. 351-366, Jul. 2016.

[136] M. Christopher and P. Tatham, Humanitarian Logistics: Meeting the Challenge of Preparing for and Responding to Disasters. London, UK: Kogan Page Publishers, 2011.

[137] A. F. Blecken and B. Hellingrath, “Supply chain management software for humanitarian operations: Review and assessment of current tools," in $5^{\text {th }}$ International ISCRAM Conference, Washington, USA, 2008, pp. 342-351.

[138] A. Lorca, M. Celik, O. Ergun, and P. Keskinocak, “A decision-support tool for post-disaster debris operations," Procedia Eng., vol. 107, pp. 154-167, 2015.

[139] L. Ozdamar, "Planning helicopter logistics in disaster relief," $O R$ Spectr., vol. 33, no. 3, pp. 655-672, Jul. 2011.

[140] S. Chowdhury, A. Emelogu, M. Marufuzzaman, S. G. Nurre, and L. Bian, “Drones for disaster response and relief operations: A continuous approximation model," Int. J. Prod. Econ., vol. 188, pp. 167-184, Jun. 2017.

[141] C. A. Thiels, J. M. Aho, S. P. Zietlow, and D. H. Jenkins, "Use of unmanned aerial vehicles for medical product transport," Air Med. J., vol. 34, no. 2, pp. 104-108, Mar. 2015.

[142] B. Rabta, C. Wankmuller, and G. Reiner, "A drone fleet model for last-mile distribution in disaster relief operations," Int. J. Disaster Risk Reduct., vol. 28, pp. 107-112, Jun. 2018.

[143] R. Al-Tahir, M. Arthur, and D. Davis, "Low cost aerial mapping alternatives for natural disasters in the caribbean," in FIG Working Week, Marrakech, Morocco, 2011, p. 050160013.

[144] L. Destro and J. Holguín, "Material convergence and its determinants," Transp. Res. Rec. J. Transp. Res. Board, vol. 2234, no. 1, pp. 14-21, Jan. 2011.

[145] J. Holguín, M. Jaller, L. N. Van, N. Pérez, and T. Wachtendorf, “Material convergence: Important and understudied disaster phenomenon," Nat. Hazards Rev., vol. 15, no. 1, pp. 1-12, Feb. 2014.

[146] A. N. Arnette and C. W. Zobel, "Investigation of material convergence in the september 2013 colorado floods," Nat. Hazards Rev., vol. 17, no. 2, pp. 0501-6001, May 2016.

[147] J. Holguín, N. Pérez, M. Jaller, L. N. Van, and F. Aros-Vera, “On the appropriate objective function for post-disaster humanitarian 
logistics models," J. Oper. Manag., vol. 31, no. 5, pp. 262-280, Jul. 2013.

[148] V. Cerullo and M. J. Cerullo, "Business continuity planning: A comprehensive approach," Inf. Syst. Manag., vol. 21, no. 3, pp. 70-78, Dec. 2006.

[149] C. W. Zobel and L. Khansa, "Characterizing multi-event disaster resilience," Comput. Oper. Res., vol. 42, pp. 83-94, Feb. 2014.

[150] G. P. Cimellaro, A. M. Reinhorn, and M. Bruneau, "Framework for analytical quantification of disaster resilience," Eng. Struct., vol. 32, no. 11, pp. 3639-3649, Nov. 2010.

[151] S. Yu, S. W. Kim, C. W. Oh, H. An, and J. M. Kim, "Quantitative assessment of disaster resilience: An empirical study on the importance of post-disaster recovery costs," Reliab. Eng. Syst. Saf., vol. 137, pp. 6-17, May 2015.

[152] (2014) World urbanization prospects: The 2014 revision. United Nations. Accessed Oct. 25, 2017. [Online]. Available: https: //bit.ly/2GMpqLk 